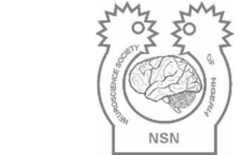

Official Journal of the Neuroscience Society of Nigeria (NSN)

\title{
Ameliorative Effects of Kolaviron on Behavioural Deficits and Oxidative Damage in Prefrontal Cortex and Hippocampus of Cuprizone-Induced Demyelinated Mice
}

\author{
Gabriel O. Omotoso ${ }^{1}$, Joseph O. Adebayo ${ }^{2}$, Olayemi J. Olajide ${ }^{1}$, Ismail T. \\ Gbadamosi $^{1}$, Bernard U. Enaibe ${ }^{1}$, Oluwole B. Akinola ${ }^{1}$ and Bamidele V. Owoyele ${ }^{3}$ \\ ${ }^{1}$ Department of Anatomy, Faculty of Basic Medical Sciences; ${ }^{2}$ Department of Biochemistry, Faculty of Life \\ Sciences; ${ }^{3}$ Department of Physiology, Faculty of Basic Medical Sciences; University of Ilorin, Ilorin, Nigeria
}

Received:

July 2020

Accepted:

September 2020

\begin{abstract}
Cuprizone neurotoxicity is commonly induced to mimic demyelinating disorders of the central nervous system, especially multiple sclerosis. This study assessed the role of kolaviron, a Garcinia kola biflavonoid, in restoring behavioural functions in cuprizone-induced neurotoxicity after termination of cuprizone treatment. Eighteen adult male Swiss albino mice aged between 6-8 weeks were randomly divided into 3 equal groups (A to $C$ ). Group A (control) mice were fed with normal rodent diet while groups $B$ and $C$ received $0.2 \%$ cuprizone diet for 5 weeks to induce demyelination; thereafter group $B$ mice with cuprizone-induced demyelination were administered corn oil $(0.5 \mathrm{~mL})$, while group $\mathrm{C}$ mice with cuprizone-induced demyelination were administered kolaviron $(200 \mathrm{mg} / \mathrm{kg} / \mathrm{d})$ for 14 days. The mice were assessed for learning, memory, anxiety and exploratory drive, and thereafter the concentration of malondialdehyde (MDA) and activities of superoxide dismutase (SOD) and glutathione peroxidase (GPx) in the prefrontal cortex and hippocampus of the mice were evaluated. Findings revealed improved behavioural outcomes in mice treated with kolaviron compared to control and the untreated cuprizone-induced demyelinated mice. There was significant reduction in SOD and GPx activities with significant increase in MDA concentration in the untreated cuprizone-induced mice compared to controls. However, there was significant increase in SOD and GPx activities with significant reduction in MDA concentration in the kolaviron-treated cuprizone-induced mice compared to those of untreated cuprizone-induced mice. The results suggest that kolaviron may effectively ameliorate the oxidative damage and behavioural deficits associated with cuprizone-induced neurotoxicity.
\end{abstract}

Key words: Cuprizone; Kolaviron; Oxidative stress; Lipid peroxidation; Behaviour

\section{INTRODUCTION}

Cuprizone-induced neurotoxicity is of immense usefulness in studying the demyelinationremyelination phenomenon associated with multiple sclerosis (MS), due to its characteristic reversibility following withdrawal of the drug (Zendedel et al. 2013). Cuprizone is a copper chelating agent often formulated into diet $(0.1 \%-0.5 \%$ cuprizone diet) for oral consumption in experimental model and causes oligodendroglial cell death with subsequent demyelination (Silvestroff et al. 2012).
Remyelination is the process whereby new myelin sheaths are formed around axons after an initial demyelination (Hanafy and Sloane 2011). Using the cuprizone model, demyelination was completed after 5 weeks and remyelination process commenced immediately after cuprizone withdrawal (Gudi et al. 2014). In the absence of any intervention, new

Correspondence: Gabriel O. Omotoso, PhD, Department of Anatomy, Faculty of Basic Medical Sciences, University of llorin, P.M.B. 1515, Ilorin 240003, Nigeria; Phone: +2347030505707; E-mail: omotoso.go@unilorin.edu.ng 
oligodendrocytes are produced from oligodendrocyte precursor cells to restore already depleted myelin sheath (Armstrong et al. 2016). It is quite possible for remyelination to occur during the course of MS lesion, although this is not adequate and does not also occur in all categories of patients with the disability (Chang et al. 2002). Hence, the potential for axonal remyelination during MS pathology differs from person to person. Some of the factors that could be responsible for impaired remyelination within MS lesions include problems associated with the processes of migration, proliferation and maturation of oligodendrocytes (Hanafy and Sloane 2011).

Natural medicinal products, including kolaviron and Moringa oleifera that possess antioxidant and antiinflammatory properties, in experimental animal models of multiple sclerosis have been demonstrated to slow down the progression of the disorder (Tasset et al. 2013; Binyamin et al. 2015; Omotoso et al. 2018 a,b,c). These studies focused on using the natural antioxidants concurrently during the demyelinating process (Omotoso et al. 2018 a-c, 2019). Some of these natural products are able to scavenge free radicals while some in conjunction with this, are able to induce the antioxidant defense system in vivo. A typical example of these natural products which uses these dual mode of actions is kolaviron (Omotoso et al. 2018a). Kolaviron is a biflavonoid complex isolated from the seeds of Garcinia kola and experimental evidence showed it has anti-oxidative and anti-inflammatory properties (Farombi et al. 2004; 2009; 2013). Our previous studies demonstrated the anti-oxidative activity of $200 \mathrm{mg} / \mathrm{kg}$ body weight of kolaviron in rodents, corroborating other works that have used similar dose of kolaviron (Farombi et al. 2013; Olajide et al. 2016; Alabi et al. 2017; Omotoso et al. 2017, 2018a, 2018b). However, a study by Ayepola et al. (2013) demonstrated equal potential of kolaviron at a lower dose of $100 \mathrm{mg} / \mathrm{kg}$ body weight, while higher dose of $400 \mathrm{mg} / \mathrm{kg}$ body weight was reported to have adverse effect.

Meanwhile, there is paucity of information on the ability of kolaviron to enhance remyelination after the demyelinating agent is withdrawn. Thus, this study was set out to evaluate the activity of kolaviron on the rate of progression of remyelination after termination of cuprizone-induced demyelination.

\section{MATERIALS AND METHODS}

\section{Ethical Approval}

The study was approved by the University Ethical Review Committee, University of Ilorin, Ilorin, Nigeria.

\section{Animal Handling}

Following ethical approval, eighteen male albino Swiss mice aged between 6-8 weeks were obtained and used for the study. They were sheltered and acclimatized in the Animal Holding Unit of the Faculty of Basic Medical Sciences, University of Ilorin, Nigeria, under hygienic and favourable conditions. The mice had free access to pelletized rodent's feeds and water ad libitum.

\section{Chemicals and Extraction of Kolaviron}

Pelletized cuprizone diet $(0.2 \%, 2018$, Red TD 140804) was procured from Envigo $\AA$, Indianapolis, USA. Garcinia kola seeds were obtained from OjaOba market, Ilorin, Nigeria. The extraction process was carried out at the Central Research Laboratory of the University of Ilorin. The voucher number (UILH/001/1217) of the seeds of Garcinia kola was deposited in the Herbarium of the Department of Plant, University of llorin. The seeds were air-dried at room temperature and pulverized into fine powder (Farombi et al. 2009; 2013; Olajide et al. 2016; Omotoso et al. 2018a). Thereafter, the powder was treated with light petroleum ether (boiling point 40-60 ${ }^{\circ} \mathrm{C}$ ) in Soxhlet extractor. The defatted dried marc obtained was repacked and extracted with acetone (boiling point $56-60{ }^{\circ} \mathrm{C}$ ). The resulting product was concentrated and diluted to twice its volume with distilled water and extracted with ethyl acetate, yielding a yellow solid substance (kolaviron). The process of determination of purity and identity of kolaviron involved subjecting the extract to thin layer chromatography using silica gel GF 254-coated plates and solvent mixture of methanol and chloroform in a ratio 1:4 (v/v). Three bands were viewed under UV light at a wavelength of $254 \mathrm{~nm}$ with 'ratio to front' values of $0.48,0.71$ and 0.76 (Farombi et al. 2009; 2013). The structure of kolaviron is shown in Figure 1.

\section{Animal Grouping and Drug Administration}

The mice were randomly grouped into 3 , with each group having 6 mice. Group A mice (control) received normal rodent chow for 5 weeks, while groups $B$ and C mice received $0.2 \%$ cuprizone diet for 5 weeks to induce demyelination. After 5 weeks, all the groups were placed on normal rodent feed and water. In addition, group $\mathrm{B}$ mice were orally administered 0.5 $\mathrm{mL}$ of corn oil (as vehicle) (Carlini, ALDI Inc. Batavia), while those in group C were orally administered kolaviron $(200 \mathrm{mg} / \mathrm{kg}$, dissolved in $0.5 \mathrm{~mL}$ of corn oil) (Adaramoye et al. 2005) once daily for 14 days. Kolaviron was administered daily between 08:00 and $9.00 \mathrm{am}$.

\section{Behavioural Assessment Learning and Memory}

At the end of the treatment regimen, the learning capacity and memory indices of the experimental animals were obtained by subjecting the experimental animals to Morris water maze and $\mathrm{Y}$ maze to evaluate their spatial and working memories respectively. 
Morris Water Maze Test for Spatial Memory

This test was carried out to assess spatial learning and memory of mice in the different treatment groups. The procedure was done in accordance with the comprehensive description by Vorhees and Williams (2006). Briefly, the test was carried out with a water tank measuring $0.9 \mathrm{~m}$ in diameter and $0.6 \mathrm{~m}$ in depth. The water-filled tank was divided into four quadrants; North-East (NE), North-West (NW), South-East (SE) and South-West (SW) with an escape platform placed one inch deep at the centre of the NW quadrant. The animals were trained three days prior to the test day. During the training, the animals were placed in each of the other three quadrants (NE, SE and SW) for a maximum period of sixty seconds to find the escape platform. Animals that were unable to find the escape platform were guided to the escape platform. This process was repeated for another two days. On the test day, the animals were placed once in each of the three quadrants maximum time of one minute and the time taken to find the escape platform was recorded as the escape latency period. Animals that were unable to find the escape platform within sixty seconds were removed and the escape latency period was recorded as $60 \mathrm{~s}$.<smiles>[R]c1ccc(C2Oc3c(c(O)cc(O)c3C3C(=O)c4c(O)cc(O)cc4OC3c3ccc(O)c([R])c3)C(=O)C2[R])cc1[R4]</smiles>

$\begin{array}{lllll} & \text { R1 } & \text { R2 } & \text { R3 } & \text { R4 } \\ \text { GB1 } & \text { OH } & \text { H } & \text { OH } & \text { H } \\ \text { GB2 } & \text { OH } & \text { H } & \text { OH } & \text { OH } \\ \text { Kolaflavanone } & \text { OH } & \text { H } & \text { OCH }_{3} & \text { OH }\end{array}$

Fig. 1: Chemical Structure of Kolaviron (Farombi et al. 2013)

\section{Y maze Test for Working Memory}

This test was used to examine working and cognitive memory in mice (Kim et al. 2013). The animals were placed in a Y-maze (without training, reward or punishment) which arms measured $75 \mathrm{~cm}$ in length and $15 \mathrm{~cm}$ in breath with an angle of $120^{\circ}$ in between arms. The animals were allowed to explore the maze for duration of $10 \mathrm{~min}$. The manner of alternation was recorded. The percentage correct alternation of each mouse was estimated as a ratio of the correct alternation to the total alternation multiplied by 100 .

\section{Anxiety and Exploratory Drive}

Anxiety and exploratory drive test was carried out as previously described by Gould et al. (2009), using the open field apparatus. The apparatus was made from a plywood measuring $100 \mathrm{~cm} \times 100 \mathrm{~cm}$ with walls 50 $\mathrm{cm}$ high. The floor was divided into square grids each measuring $25 \mathrm{~cm}$ in length with a blue marker and a centre square of the same length was drawn with a red marker. During the test, the rats were picked by their tails and dropped in the centre square and allowed to explore for $5 \mathrm{~min}$, while the video was captured by a camera placed above the apparatus. Six behaviours were scored: the number of lines crossed, centre square entry, centre square duration, freezing duration, rearing frequency and stretch attend posture frequency.

\section{Preparation of Homogenates of Brain Tissues and Biochemical Analysis}

At the end of the experiments, the animals were sacrificed by cervical dislocation; each brain was removed and the prefrontal cortex and hippocampus were excised. Equal weighing brain tissues were homogenized in $0.25 \mathrm{M}$ sucrose solution $(1: 5, \mathrm{w} / \mathrm{v})$ with an automated homogenizer at $4{ }^{\circ} \mathrm{C}$. The homogenates were frozen overnight to allow complete cell lysis and maximum release of enzymes (Akanji et al. 1993). The tissue homogenate was centrifuged for $10 \mathrm{~min}$ in a microfuge at $12,000 \mathrm{rpm}$ to obtain the supernatant containing organelle fragments and synaptosomes. The supernatants were aspirated into plain labelled glass cuvette placed in ice. SOD (KT-60703), GPx (MBS-744364) activities and MDA (MBS-9389391) concentration in the supernatants of prefrontal cortex and hippocampus were assayed using spectrophotometric techniques (Thiha and Ibrahim 2015).

\section{Statistical Analysis}

All quantitative data were analysed using the GraphPad Prism® software (version 6). SOD, GPx, and MDA outcomes were plotted in analysis of variance (ANOVA) with Tukey's multiple comparisons test. Significance was set at $p<0.05$ or 0.01 . The outcomes were represented in bar charts with error bars to show the mean and standard error of mean (SEM).

\section{RESULTS}

\section{Kolaviron Ameliorates Cuprizone-Induced} Behavioural Deficits after Cuprizone Withdrawal The findings from the behavioural analysis revealed that the untreated demyelinated mice exhibited a 
significantly higher $(p<0.05)$ escape latency (longterm memory index) period after 2 weeks postdemyelination compared to control (Fig. 2). The results also revealed that kolaviron significantly $(p<0.05)$ reduced the escape latency period of mice that were treated with kolaviron for two weeks postdemyelination compared to the untreated demyelinated mice, restoring it to the range of control $(p>0.05)$. However, the untreated demyelinated mice and kolaviron-treated demyelinated mice had percentage correct alternation which were not significantly different $(p>0.05)$ from the control. The behavioural scores for the number of lines crossed, centre square entry, centre square duration and rearing frequency were significantly reduced $(p<0.05)$ while the stretch-attend posture frequency and freezing duration of the untreated demyelinated mice were significantly increased $(p<0.05)$ compared to controls (Fig. 3 ). The results revealed that kolaviron was able to revert the observed alteration in these parameters caused by cuprizone-induced demyelination to the range of controls $(p>0.05)$.

\section{Biochemical Parameters}

Assessment of MDA level was used to determine the degree of lipid peroxidation. In this study, the results revealed that there was no significant alteration $(p>0.05)$ in MDA concentrations in the prefrontal cortex and hippocampus of the untreated cuprizoneinduced demyelinated mice and the kolaviron-treated cuprizone-induced demyelinated mice compared to controls (Fig. 4).

There was significant reduction $(p<0.05)$ in SOD activities in both the prefrontal cortex and hippocampus of untreated cuprizone-induced demyelinated mice compared to those of kolavirontreated cuprizone-induced mice and controls (Fig. 5). However, there was no significant change $(p>0.05)$ in
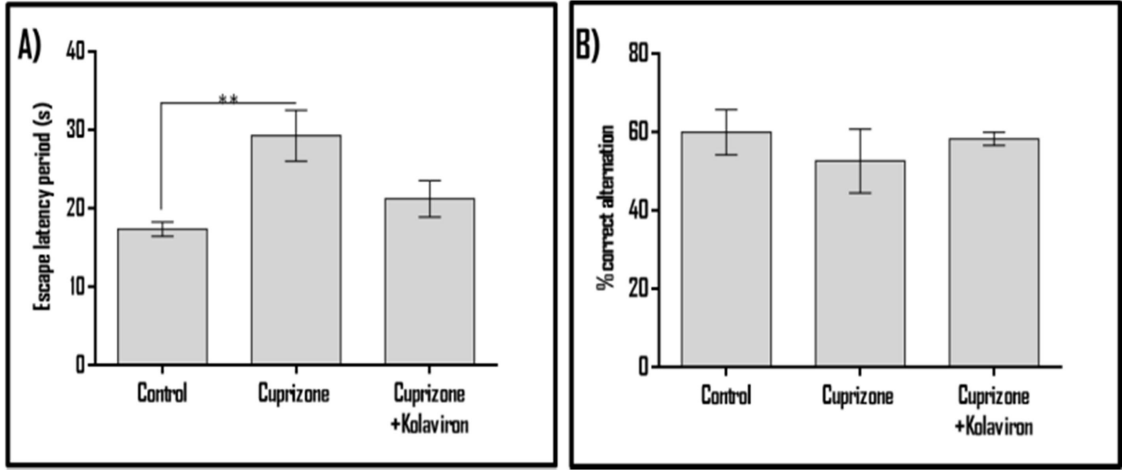

Fig. 2: Neurobehavioural Outcomes of Experimental Animals in the Morris Water (A) and Y- mazes (B). Cuprizone-treated mice had a significantly high escape latency period in the Morris water maze when compared to the control $(p<0.01)$ and kolaviron-treated animals $(p>0.05)$. For the $Y$-maze test, the cuprizone-treated mice presented with a lower percentage correct alternation relative to the control group and the group post-treated with kolaviron $(p>0.05)$. ${ }^{* *}$ is significant value of $p<0.01$. Control= regular diet for 5 weeks; Cuprizone group $=$ cuprizone $(5$ weeks $)+$ corn oil (2 weeks); Cuprizone + Kolaviron = cuprizone (5 weeks) + kolaviron (2 weeks).
SOD activities in both the prefrontal cortex and hippocampus of kolaviron-treated cuprizone-induced mice compared to controls.

peroxidase activities in the prefrontal cortex and hippocampus of the untreated demyelinated mice and the kolaviron-treated mice were not significantly altered ( $p>0.05$ ) compared to controls (Fig. 6).

\section{DISCUSSION}

The search for novel drugs for the treatment of MS has led to the development of a broad range of animal models of demyelination (Blakemore and Franklin 2008; Geurts and Barkhof 2008; Guo et al. 2018; Mecha et al. 2019). Nevertheless, the intricacy of MS pathogenesis makes none of these models flect the whole spectrum of MS. The chemical model is the most used of the demyelination experimental models because of the predictable inetics. Compared to other models, cuprizone model is remarkably appreciated in appraising and developing new re-myelination therapeutic approaches (Blakemore and Franklin 2008; Acs et al. 013; Harlow et al. 2015; Ghaiad et al. 2017; reported various therapeutic approaches to the enhancement of re-myelination, such as ancement of intrinsic antioxidant defence system (Hanwell and Banwell 2011; Tavakoli-Yaraki et al. 2018), induced neurotrophin recruitment (Zhang et al. 2011), immunomodulation (Hanafy and Sloane 2011) modulation of intrinsic signalling pathways (Harlow et al. 2015). It is believed that any natural or synthetic product which can enhance re-myelination through any of these mechanisms will be of tremendous benefit in the treatment of MS.

Exploration of phytochemicals with medicinal properties and elucidating the molecular mechanisms underlying their pharmacological activities have been very important approaches in drug discovery which has continued to gain grounds over the past few decades (Szabados et al. 2004; Balunas and Kinghorn 2005; Harvey 2008; Libro et al. 2016). In the present study, kolaviron, which has been documented to have numerous medicinal properties (Farombi and Owoeye 2011; Adedara et al. 2015; Olajide et al. 2016), was evaluated for its potential to induce re-myelination through enhancement of intrinsic antioxidant defence system. 
Hippocampal demyelination is directly linked to cognitive impairment in MS patients (Geurts et al. 2007; Geurts and Barkhof 2008; Dutta et al. 2011). The results of this study also revealed that cuprizone treatment caused reduced escape latency of experimental animals suggesting impaired spatial memory, which has been reported to occur essentially through demyelination (Kouts-oudaki et al.

experimental animals treated with or without kolaviron following due demyelination. Memory enhancing properties of kolaviron have been extensively documented (Ishola et al. 2017; Omotoso et al. 2018b; 2019). The mice with cuprizone-induced demyelination treated with kolaviron had their escape latency and percentage correct alternation reverted to the range of controls, suggesting that kolaviron was able to enhance the
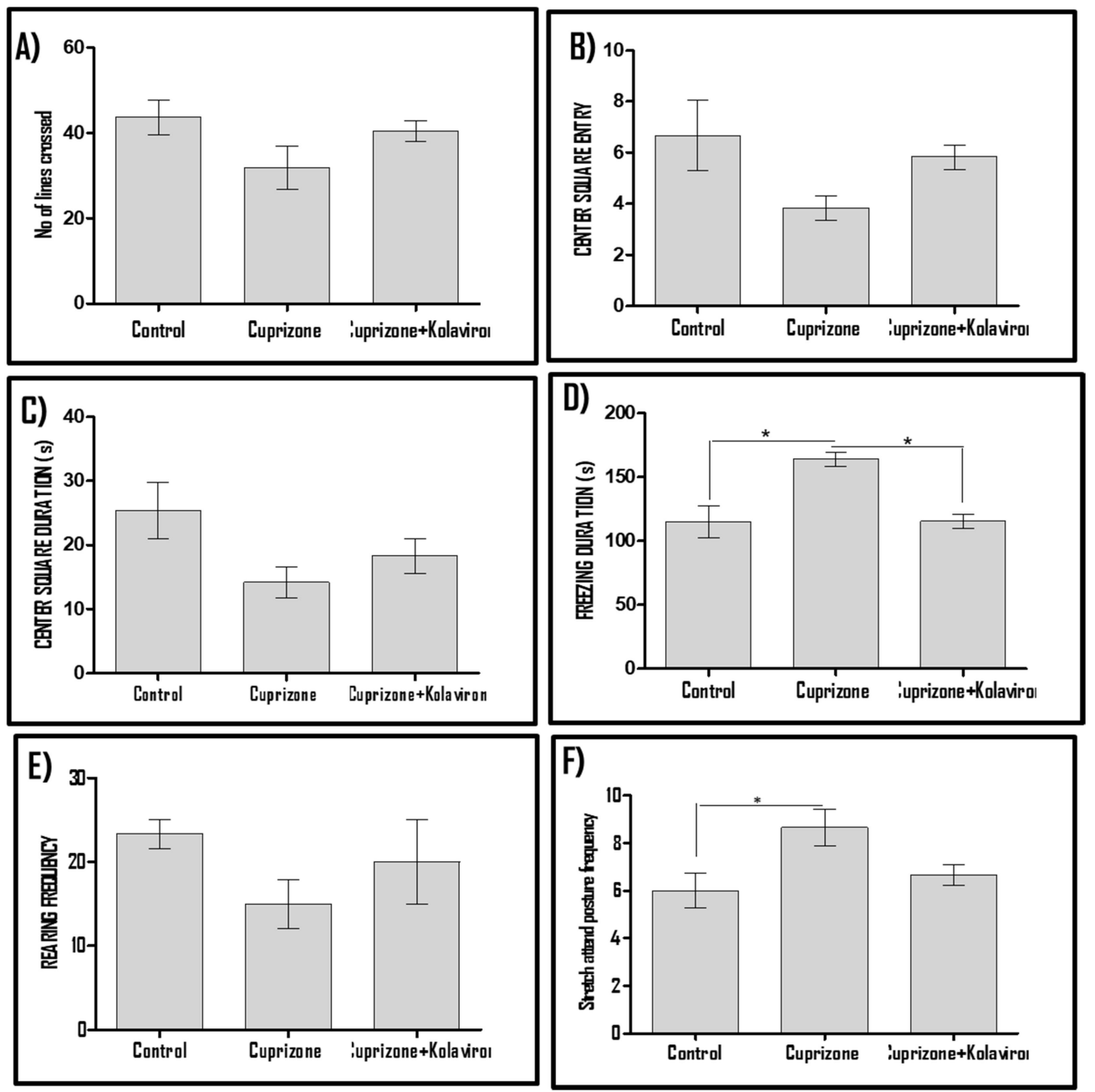

Fig. 3: Behavioural analysis of mice in the open field behavioral paradigm. Figures $A$ to $F$ represented number of lines crossed, center square entry, center square duration, freezing duration, rearing frequency and stretch attend posture frequency respectively. The behavioral scores for the number of lines crossed, center square entry, center square duration and rearing frequency were relatively higher in mice that received kolaviron post-cuprizone treatment relative to the untreated cuprizone-induced mice $(p>0.05)$. The untreated cuprizone-induced group had a significantly higher freezing duration and stretch attend posture frequency relative to the control and kolaviron-treated group $(p<0.05)$. ${ }^{*}$ Significantly different at $p<0.05$.

2009; Norkute et al. 2009), thus corroborating earlier reports (Geurts and Barkhof, 2008; Dutta et al. 2011). Functional re-myelination in the present study was inferred from behavioural analysis of the spatial and working memories of the mice compared to the untreated demyelinated mice. It also suggests that kolaviron enhanced restoration of long- and short -term memory indices of the mice.

Anxiety is one of the core clinical manifestations in patients suffering from demyelinating diseases (Simpson et al. 2016). High freezing duration and stretchattend posture frequency are open field test parameters used to assess the presence of anxiety in rodents. In this study, untreated cuprizone-induced demyelinated mice had higher freezing duration and stretch-attend posture frequency compared to controls, suggesting anxiety in the animals. This finding corroborates previous reports on the anxiogenic properties of cuprizone (Franco-Pons et al. 2007; Zhang et al. 2013). The results also revealed that kolaviron effectively reversed the increased anxiety indices in demyelinated mice to the range of controls. This finding suggests that kolaviron did not only enhance quick and functional remyelination, it also exhibited anxiolytic properties that counter-balanced cuprizone-induced anxiety. Spatial exploration indices were reduced in the untreated demyelinated mice compared to controls, suggesting cuprizone-induced perturbation 
of spatial navigation. Treatment with kolaviron restored the spatial exploration indices to the range of controls.

Oxidative stress has been implicated in the pathogenesis of demyelinating diseases (Offen et al. 2004; di Penta et al. 2013; Wang et al. 2014; Lassmann and van Horssen 2016; Ghaiad et al. 2017). SOD and GPx are key antioxidant enzymes that scavenge superoxide radical and hydrogen peroxide respectively (MatÉs et al. 1999; Chiang.et al. 2006; Gbadamosi et al. 2016). Cuprizone is known to reduce the activities of these enzymes and mediate a cascade of biochemical reactions that lead to superfluous generation of reactive oxygen species, which culminates in lipid peroxidation (Omotoso et al. 2018a, b). MDA is a product derived from the peroxidation of polyunsaturated fatty acids and it is commonly used to assess lipid peroxidation (Gentile et al. 2017). In the present study, the MDA concentrations and GPx activities were not significantly altered in the untreated demyelinated mice and kolaviron-treated demyelinated mice compared to controls. However, SOD activities in the prefrontal cortex and hippocampus were significantly reduced in untreated demyelinated mice, but not changed in kolaviron-treated demyelinated mice compared to controls. These results suggest that in the absence of any intervention, withdrawal of cuprizone treatment does not immediately resolve the reduction in SOD activity which characterizes cuprizone neurotoxicity. However, kolaviron was able to reverse SOD activity to the range of control, thus
MDA
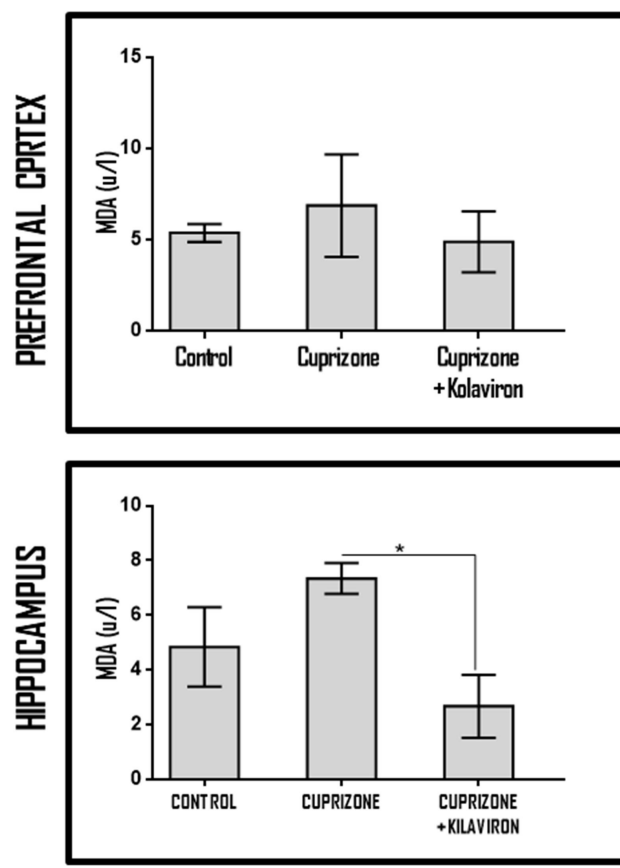

Fig. 4: Effects of kolaviron on malondialdehyde concentrations in the prefrontal cortex and hippocampus of cuprizoneinduced demyelinated mice. MDA remained elevated in the prefrontal cortex and hippocampus of mice exposed to cuprizone for 5 weeks followed by regular diets for 2 weeks (cuprizone group), while mice that received kolaviron for 2 weeks immediately post-cuprizone treatment (cuprizone+kolaviron group) had the least levels of MDA in both prefrontal cortex and hippocampus $\quad(p>0.05)$. Significantly different at $p<0.05$.
GPx
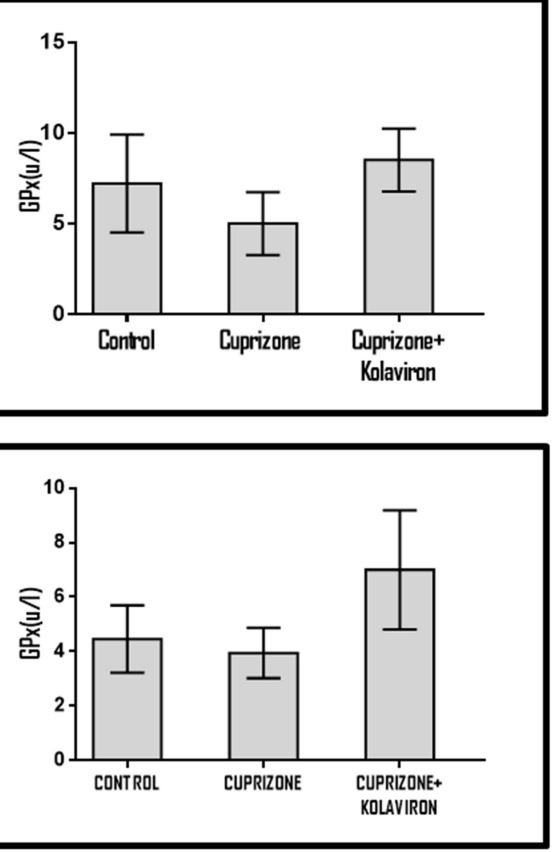

Fig. 5: Effects of kolaviron on superoxide dismutase activities in the prefrontal cortex and hippocampus of mice. SOD was reduced in untreated cuprizoneinduced mice (cuprizone group) compared with kolaviron-treated cuprizone-induced mice (cuprizone + kolaviron) $\quad(p<0.05) . \quad$ *Significant difference at $p<0.05$.

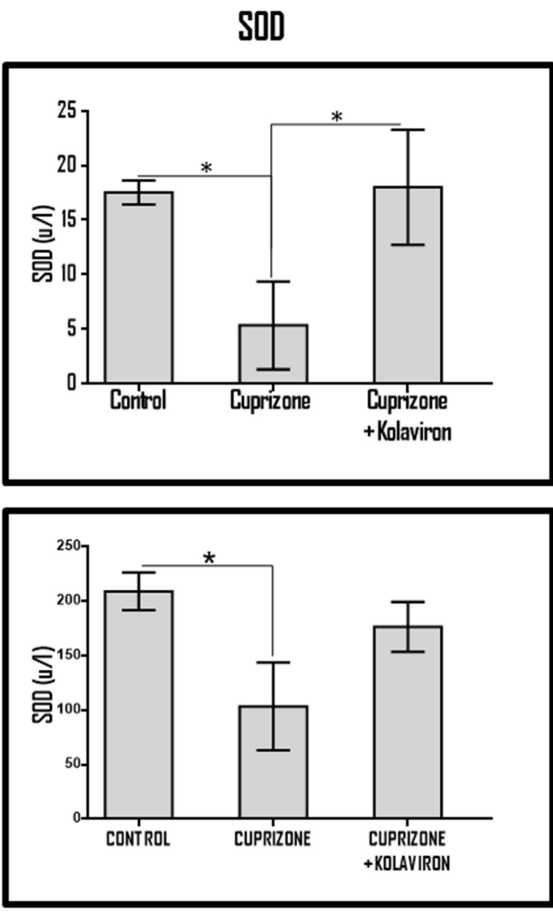

Fig. 6: Effects of kolaviron on glutathione peroxidase activities in the prefrontal cortex and hippocampus of cuprizoneinduced demyelinated mice. Both prefrontal cortex and hippocampus had reduced levels of GPx in untreated cuprizone-induced mice (cuprizone group), but increased values in kolaviron-treated cuprizone-induced mice (cuprizone + kolaviron) ( $p>0.05)$. 
enhancing the first line of enzymic antioxidant defence to combat the oxidative stress induced by cuprizone.

The results of this study therefore suggests that kolaviron possesses the potential of enhancing remyelination in MS subjects by inducing antioxidant defence system, thereby alleviating memory and behavioural deficits associated with MS.

\section{Acknowledgment}

The authors are grateful for the Institutional-based Intervention Research Grant received from the Tertiary Education Trust Fund through the University of Ilorin, Ilorin, Nigeria, to carry out the study.

\section{REFERENCES}

Acs, P., Selak, M.A., Komoly, S. and Kalman, B. (2013) Distribution of oligodendrocyte loss and mitochondrial toxicity in the cuprizone-induced experimental demyelination model. Journal of Neuroimmunology. 262:128-131.

Adaramoye, O.A., Nwaneri, V.O., Anyanwu, K.C., Farombi, E.O. and Emerole, G.O. (2005) Possible anti-atherogenic effect of kolaviron (a Garcinia kola seed extract) in hypercholesterolaemic rats. Clinical and Experimental Pharmacology and Physiology. 32(1-2):40-46.

Adedara, I.A., Owoeye, O., Aiyegbusi, M.A., Dagunduro, J.O., Daramola, Y.M. and Farombi, E.O. (2015) Kolaviron protects against benzo[a]pyreneinduced functional alterations along the brainpituitary-gonadal axis in male rats. Environmental Toxicology and Pharmacology. 40:459-470.

Akanji, M.A., Olagoke, O.A. and Oloyede, O.B. (1993) Effect of chronic consumption of metabisulphite on the integrity of rat kidney cellular system. Toxicology. 8:173-179.

Alabi, Q.K., Akomolafe, R.O., Olukirana, O.S., Adeyemi, W.J., Nafiu, A.O., Adefisayo, M.A., et al. (2017) The Garcinia kola biflavonoid kolaviron attenuates experimental hepatotoxicity induced by diclofenac. Pathophysiology. 24:281-290.

Armstrong, R.C., Mierzwa, A.J., Sullivan, G.M. and Sanchez, M.A. (2016) Myelin and oligodendrocyte lineage cells in white matter pathology and plasticity after traumatic brain injury. Neuropharmacology. 110: 654-659.

Ayepola, O.R., Chegou, N.N., Brooks, N.L. and Oguntibeju, O.O. (2013) Kolaviron, a Garcinia biflavonoid complex ameliorates hyperglycemiamediated hepatic injury in rats via suppression of inflammatory responses. BMC Complementary and Alternative Medicine. 13:363. doi:10.1186/14726882-13-363.

Balunas, M.J. and Kinghorn, A.D. (2005) Drug discovery from medicinal plants. Life Sciences. 78:431-441.
Binyamin, O., Larush, L., Frid, K., Keller, G., Friedman-Levi, Y., Ovadia, H., et al. (2015) Treatment of a multiple sclerosis animal model by a novel nanodrop formulation of a natural antioxidant. International Journal of Nanomedicine. 10:71657174.

Blakemore, W.F. and Franklin, R.J.M. (2008) Remyelination in experimental models of toxininduced demyelination. Current Topics in Microbiology and Immunology. 318:193-212.

Chang, A., Tourtellotte, W.W., Rudick, R. and Trapp, B.D. (2002) Premyelinating oligodendrocytes in chronic lesions of multiple sclerosis. New England Journal of Medicine. 346:165-173.

Chiang, A.-N., Wu, H.-L., Yeh, H.-I., Chu, C.-S., Lin, H.-C. and Lee, W.-C. (2006) Antioxidant effects of black rice extract through the induction of superoxide dismutase and catalase activities. Lipids. 41:797-803. di Penta, A., Moreno, B., Reix, S., Fernandez-Diez, B., Villanueva, M., Errea, O., et al. (2013) Oxidative stress and proinflammatory cytokines contribute to demyelination and axonal damage in a cerebellar culture model of neuroinflammation. PLoS One. 8: e54722.https://doi.org/10.1371/journal.pone.0054722 Dutta, R., Chang, A., Doud, M.K., Kidd, G.J., Ribaudo, M.V., Young, E.A., et al. (2011) Demyelination causes synaptic alterations in hippocampi from multiple sclerosis patients. Annals of Neurology. 69:445-454.

Farombi, E.O. and Owoeye, O. (2011). Antioxidative and Chemopreventive Properties of Vernonia amygdalina and Garcinia biflavonoid. International Journal of Environmental Research and Public Health. 8: 2533-2555.

Farombi, E., Møller, P. and Dragsted, L.O. (2004) Exvivo and in vitro protective effects of kolaviron against oxygen-derived radical-induced DNA damage and oxidative stress in human lymphocytes and rat liver cells. Cell Biology and Toxicology. 20:71-82.

Farombi, E.O., Adedara, I.A., Ajayi, B.O., Ayepola, O.R. and Egbeme, E.E. (2013) Kolaviron, a natural antioxidant and anti-inflammatory phytochemical prevents dextran sulphate sodium-induced colitis in rats. Basic and Clinical Pharmacology and Toxicology. 113(1):49-55.

Farombi, E.O., Shrotriya, S. and Surh, Y.-J. (2009) Kolaviron inhibits dimethyl nitrosamine-induced liver injury by suppressing COX-2 and iNOS expression via NF-kB and AP-1. Life Sciences. 84:149-155.

Franco-Pons, N., Torrente, M., Colomina, M.T. and Vilella, E. (2007) Behavioral deficits in the cuprizoneinduced murine model of demyelination/ remyelination. Toxicology Letters. 169: 205-213.

Gbadamosi, I.T., Omotoso, G.O., Olajide, O.J., DadaHabeeb, S.O., Arogundade, T.T., Lambe, E., et al. (2016) Moringa protects against nicotine-induced morphological and oxidative damage in the frontal cortex of Wistar rats. Anatomy. 10:170-176.

Gentile, F., Arcaro, A., Pizzimenti, S., Daga, M., Cetrangolo, G.P., Dianzani, C., et al. (2017) DNA 
damage by lipid peroxidation products: implications in cancer, inflammation and autoimmunity. AIMS Genetics. 4(2):103-137.

Geurts, J.J. and Barkhof, F. (2008) Grey matter pathology in multiple sclerosis. The Lancet Neurology. 7: 841-851.

Geurts, J.J.G., Bö, L., Roosendaal, S.D., Hazes, T., Daniëls, R., Barkhof, F. et al. (2007) Extensive hippocampal demyelination in multiple sclerosis. Journal of Neuropathology and Experimental Neurology. 66:819-827.

Ghaiad, H.R., Nooh, M.M., El-Sawalhi, M.M. and Shaheen, A.A. (2017) Resveratrol promotes remyelination in cuprizone model of multiple sclerosis: biochemical and histological study. Molecular Neurobiology. 54:3219-3229.

Gould, T.D., Dao, D.T. and Kovacsics, C.E. (2009) The open field test. In: mood and anxiety related phenotypes in mice: characterization using behavioral tests. Neuromethods. 42:1-20

Gudi, V., Gingele, S., Skripuletz, T. and Stangel, M. (2014) Glial response during cuprizone-induced deand remyelination in the CNS: lessons learned. Frontiers in Cellular Neuroscience. 8:73. doi:10:3389/ fncel.2014.00073.

Guo, Y., Suo, N., Cui, X., Yuan, Q. and Xie, X. (2018) Vitamin $\mathrm{C}$ promotes oligodendrocytes generation and remyelination. Glia. 66:1302-1316. doi: 10.1002/glia.23306.

Hanafy, K.A. and Sloane, J.A. (2011) Regulation of remyelination in multiple sclerosis. FEBS Letters. 585:3821-3828.

Hanwell, H.E.C. and Banwell, B. (2011) Assessment of evidence for a protective role of vitamin $D$ in multiple sclerosis. Biochimica et Biophysica Acta. 1812: 202-212.

Harlow, D.E., Honce, J.M. and Miravalle, A.A. (2015) Remyelination therapy in multiple sclerosis. Frontiers in Neurology. 6: 1-13. https://doi.org/10.3389/fneur.2 015.00257.

Harvey, A.L (2008) Natural products in drug discovery. Drug Discovery Today. 13: 894-901.

Ishola, I.O., Adamson, F.M., Adeyemi, O.O. (2017) Ameliorative effect of kolaviron, a biflavonoid complex from Garcinia kola seeds against scopolamine-induced memory impairment in rats: role of antioxidant defense system. Metabolic Brain Disease. 32:235-245.

Kim, S.M., Kim, H., Lee, J.S., Park, K.S., Jeon, G.S., Shon, J., et al. (2013) intermittent hypoxia can aggravate motor neuronal loss and cognitive dysfunction in ALS mice. PLoS One. 8:e81808. https://doi.org/10.1371/journal.pone.0081808

Koutsoudaki, P.N., Skripuletz, T., Gudi, V., Moharregh-Khiabani, D., Hildebrandt, H., Trebst, C., et al. (2009) Demyelination of the hippocampus is prominent in the cuprizone model. Neuroscience Letters. 451: 83-88.

Lassmann, H. and van Horssen, J. (2016) Oxidative stress and its impact on neurons and glia in multiple sclerosis lesions. Biochimica et Biophysica Acta. 1862:506-510.

Libro, R., Giacoppo, S., Rajan, T.S. and Bramanti, P. (2016) Natural phytochemicals in the treatment and prevention of dementia: an overview. Molecules. 21(4):518.https://doi.org/10.3390/molecules21040518 MatÉs, J.M., Pérez-Gómez, C. and De Castro, I.N. (1999) Antioxidant enzymes and human diseases. Clinical Biochemistry. 32:595-603.

Mecha, M., Yanguas-Casás, N., Feliú, A., Mestre, L., Carrillo-Salinas, F., Azcoitia, I., et al. (2019) The endocannabinoid 2-AG enhances spontaneous remyelination by targeting microglia. Brain, Behavior and Immunity. 77:110-126.

Norkute, A., Hieble, A., Braun, A., Johann, S., Clarner, T., Baumgartner, W., et al. (2009) Cuprizone treatment induces demyelination and astrocytosis in the mouse hippocampus. Journal of Neuroscience Research. 87:1343-1355.

Offen, D., Gilgun-Sherki, Y. and Melamed, E. (2004) The role of oxidative stress in the pathogenesis of multiple sclerosis: The need for effective antioxidant therapy. Journal of Neurology. 251: 261-268.

Olajide, O.J., Akinola, B.O., Ajao, S.M. and Enaibe, B.U. (2016) Sodium azide-induced degenerative changes in the dorsolateral prefrontal cortex of rats: attenuating mechanisms of kolaviron, European Journal of Anatomy. 20(1):47-64.

Omotoso, G.O., Gbadamosi, I.T., Afolabi, T.T., Abdulwahab A.B., Akinlolu, A.A. (2018c) Ameliorative effects of moringa on cuprizone-induced memory decline in rat model of multiple sclerosis. Anatomy and Cell Biology. 51: 119-127.

Omotoso, G.O., Olajide, O.J., Gbadamosi, I.T., Rasheed, M.A. and Izuogu, C.T. (2018a) Kolaviron protects the prefrontal cortex and hippocampus against histomorphological and neurobehavioral changes in cuprizone model of multiple sclerosis. Malaysian Journal of Medical Sciences. 25(2):50-63. Omotoso, G.O., Olajide, O.J., Gbadamosi, I.T., Suleiman, F.A. and Oladimeji, J.O. (2017) Kolaviron ameliorates histomorphological changes associated with cuprizone-induced cerebellar damage. The Journal of Anatomical Sciences. 8(2):131-137.

Omotoso, G.O., Ukwubile, I.I., Arietarhire, I., Sulaimon, F.A. and Gbadamosi, I.T. (2018b) Kolaviron protects the brain in cuprizone-induced model of experimental multiple sclerosis via enhancement of intrinsic antioxidant mechanisms: Possible Therapeutic Applications? Pathophysiology. 25(4):299-306.

Omotoso, G.O., Olajide, O.J., Gbadamosi, I.T., Adebayo, J.O., Enaibe, B.U., Akinola, O.B. and Owoyele, B.V. (2019) Cuprizone toxicity and Garcinia kola biflavonoid complex activity on hippocampal morphology and neurobehaviour. Heliyon. 5(7): e02102. doi:10.1016/j.heliyon.2019.e02102.

Silvestroff, L., Bartucci, S., Pasquini, J. and Franco, P. (2012) Cuprizone-induced demyelination in the rat cerebral cortex and thyroid hormone effects on 
cortical remyelination. Experimental Neurology. 235(1):357-367.

Simpson, S., Tan, H., Otahal, P., Taylor, B., Ponsonby, A.L., Lucas, R.M., et al. (2016) Anxiety, depression and fatigue at 5-year review following CNS demyelination. Acta Neurologica Scandinavica. 134:403-413.

Szabados, T., Dul, C., Majtényi, K., Hargitai, J., Pénzes, Z. and Urbanics, R. (2004) A chronic Alzheimer's model evoked by mitochondrial poison sodium azide for pharmacological investigations. Behavioural Brain Research. 154:31-40.

Tasset, I., Bahamonde, C., Agüera, E., Conde, C., Cruz, A.H., Pérez-Herrera, A., et al. (2013) Effect of natalizumab on oxidative damage biomarkers in relapsing-remitting multiple sclerosis. Pharmacological Reports. 65(3): 624-631.

Tavakoli-Yaraki, M., Rousta, A.M., Shahmohammadi, A., Shakeri, S., Pourvali-Talatappeh, P., Mahjoob, A., et al. (2018) A review on potential roles of vitamins in incidence, progression, and improvement of multiple sclerosis. eNeurologicalSci. 10:37-44.

Thiha, A. and Ibrahim, F. (2015) A colorimetric enzyme-linked immunosorbent assay (ELISA) detection platform for a point-of-care Dengue detection system on a lab-on-compact-disc. Sensors (Basel). 15(5):11431-11441.

Vorhees, C.V. and Williams, M.T. (2006) Morris water maze: procedures for assessing spatial and related forms of learning and memory. Nature Protocols. 1:848-858.

Wang, P., Xie, K., Wang, C. and Bi, J. (2014) Oxidative stress induced by lipid peroxidation is related with inflammation of demyelination and neurodegeneration in multiple sclerosis. European Neurology. 72:249-254.

Zendedel, A., Beyer, C. and Kipp, M. (2013) Cuprizone-induced demyelination as a tool to study remyelination and axonal protection. Journal of Molecular Neuroscience. 51(2):567-72.

Zhang, H., Zhang, Y., Xu, H., Wang, L., Zhao, J., Wang, J., et al. (2013) Locomotor activity and anxiety status, but not spatial working memory, are affected in mice after brief exposure to cuprizone. Neuroscience Bulletin. 29:633-641.

Zhang, J., Kramer, E.G., Asp, L., Dutta, D.J., Navrazhina, K., Pham, T., et al. (2011) Promoting myelin repair and return of function in multiple sclerosis. FEBS Letters. 585: 3813-3820.

Cite as: Omotoso, G.O., Adebayo, J.O., Olajide, O.J., Gbadamosi, I.T., Enaibe, B.U., Akinola, O.B. and Owoyele, B.V. (2020). Ameliorative effects of kolaviron on behavioural deficits and oxidative damage in prefrontal cortex and hippocampus of cuprizone-induced demyelinated mice.. Nig. J. Neurosci. 11(2):53-61. http://doi.org/10.47081/njn2020.11. $2 / 001$

(C) Copyright Nigerian Journal of Neuroscience. All rights reserved. 